\title{
Substance use and misuse in the aftermath of terrorism. A Bayesian meta-analysis
}

\author{
Charles DiMaggio ${ }^{1,2}$, Sandro Galea ${ }^{1,3}$ \& Guohua $\mathbf{L i}^{1,2}$ \\ Department of Epidemiology, Columbia University, Mailman School of Public Health, New York, NY, USA,' Department of Anesthesiology, Columbia University, \\ College of Physicians and Surgeons, New York, NY, USA² and Center for Social Epidemiology and Population Health, University of Michigan, Ann Arbor MI, USA ${ }^{3}$
}

\section{ABSTRACT}

Aim To conduct a comprehensive analysis of the conflicting evidence on substance use and misuse following mass traumas such as terrorist incidents. Methods We reviewed and synthesized evidence from 31 population-based studies using Bayesian meta-analysis and meta-regression. Results The majority of the studied were conducted in the aftermath of the terrorist attacks of 11 September 2001. Controlling for exposure, type of incident and time since the event occurred, $7.3 \%$ [95\% credible interval (CrI) 1.1-32.5\%] of a population can be expected to report increased alcohol consumption in the first 2 years following a terrorist event. There is, however, a $20 \%$ probability that the prevalence will be as high as 14\%. The unadjusted prevalence of increased cigarette smoking following a terrorist event is $6.8 \%$ (95\% Cr I 2.6-16.5\%). Unadjusted reports of mixed drug use (including narcotics and prescription medications) was $16.3 \%$ (95\% Cr I 1.3-72.5\%). Conclusions These results underscore the potentially pervasive behavioral health effects of mass terrorism, and suggest that public health interventions may usefully consider substance use as an area of focus after such events.

Keywords Alcohol, Bayesian, meta-analysis, meta-regression, smoking, substance, terrorism.

Correspondence to: Charles DiMaggio, Department of Epidemiology, Mailman School of Public Health, 722 West 168 St, Room 1117 , New York, NY 10032, USA. E-mail: cjd11@columbia.edu

Submitted 16 June 2008; initial review completed 6 October 2008; final version accepted 19 December 2008

\section{INTRODUCTION}

The psychological consequences of terrorist incidents have received considerable attention, particularly in the aftermath of the 1995 Oklahoma City bombings, the terrorist attacks of 11 September 2001 in the United States, and the more recent 11 March 2004 (Madrid) and 7 June 2005 (London) bombings. Several reports have documented substantial psychopathology after these attacks in each of their respective cities [1-4]. A recent metaanalysis of psychopathology in the aftermath of terrorism found that the prevalence of post-traumatic stress disorder (PTSD) in directly affected populations in the year following a terrorist incident ranges between $12 \%$ and $16 \%$ [5]. In contrast to the evidence on psychopathology, the nascent literature on substance use and misuse following mass trauma such as terrorist attacks is characterized by conflicting results $[6,7]$.
Most of the available recent evidence comes from studies conducted in the aftermath of the 11 September 2001 terrorist attacks in New York City. There were early indications of an increase in drug-seeking behavior among Manhattan residents following the terrorist attacks of 11 September 2001. Studies suggested an increase in use of certain substances, particularly cigarettes, alcohol and marijuana [7,8], in the general population and there were reports of increased alcohol and tobacco use among drug users [6]. Some researchers found evidence of persistently elevated prevalence of psychological distress many months afterwards and at long distances from the events of 11 September 2001 [9], and concluded that such stress may have "contributed to symptom severity and the utilization of urgent health care services . . . in the NYC metropolitan area' [10], as well as to non-adherence to medication regimens [11]. More recently, there have been reports of increased

Charles DiMaggio originated the study, conducted the analyses and wrote the first draft of the report. Sandro Galea and Guohua Li suggested and guided analyses, and contributed to the interpretation of the data. All authors contributed to drafting and critical revision of the manuscript for important intellectual content. 
cigarette use in the general population in the months following the terrorist attacks of 11 September 2001 [12], a finding that was echoed in a study of a cohort of military personnel also concerned with the same event [13].

However, in early research conducted after the Oklahoma City bombings of 1995, investigators concluded: 'The majority of pre-disaster alcohol and drug use disorders were reported as inactive after the disaster' and that 'Only those persons with PTSD that was complicated by comorbidity were using medication or alcohol as a coping mechanism' [3]. The distinction between alcohol and substance use following the Oklahoma City bombing and that following the 11 September attacks may not be so clear-cut, however. Follow-up studies have provided evidence of increased alcohol use among Oklahoma City fire fighters [14] and in the general population [15]. Similarly, there were reports of increased alcohol consumption among Oklahoma City Red Cross workers [16] and body handlers [17].

Further compounding uncertainty around the topic, while there is evidence to suggest that residential proximity to a disaster influences subsequent behavioral health pathology including substance use [18], this relation has not been well characterized and has sometimes been the subject of dispute [19-21].

To our knowledge, no comprehensive review and analysis of the evidence about the risk for substance use and misuse following terrorist incidents has been conducted. We undertook such a review using the tools of Bayesian meta-regression to synthesize quantitative studies of the effects of terrorism on substance use and misuse.

\section{METHODS}

In this paper, we try to address these questions: (i) what is the prevalence of addictive behavior seen after terrorist incidents; (ii) what is the probability that a population will experience an increase in addictive behavior following a terrorist incidence; and (iii) do these behaviors vary by person (survivors, treatment groups, general population, employment groups) and outcome (alcohol use and misuse, drug use, cigarette smoking) studied?

Meta-analysis provides methods for synthesizing the available evidence to answer these questions by allowing us to determine how widely study results vary, calculate an overall mean effect size and determine the relationship of other, potentially explanatory variables, such as type of sample and outcome studied to this effect size.

As in traditional meta-analyses, we chose a similar effect variable for all the studies and weighted this variable by the inverse of its variance, so that studies with larger sample sizes received relatively greater weights. Our two main-effects sizes were the prevalence of reported addictive behaviors such as alcohol use and misuse or cigarette smoking in an affected population and the odds ratio (OR) for association between an addictive behavior and a potential explanatory variable, such as the time since a terrorist incident occurred. We adopted a random-effects model, which assumes that in addition to subject-level variation there is additional random variation among studies.

We expanded on traditional meta-analytical techniques by applying Bayesian concepts. In a Bayesian approach, our two main sources of information about the synthesized effect size $(\theta)$ are our prior beliefs or the prior distribution of the parameter $(\operatorname{Pr}[\theta])$ and the likelihood of observing the data given that prior belief or distribution $(\operatorname{Pr}[\mathrm{y} \mid \theta])$. The result of combining the prior distribution and the likelihood is called the posterior distribution and follows Bayes' Theorem:

$$
\operatorname{Pr}[\theta \mid \mathrm{y}] \alpha \operatorname{Pr}[\mathrm{y} \mid \theta] * \operatorname{Pr}[\theta] .
$$

Our prior distribution is essentially what we believe the synthesized effect size $\theta$ would be and how it would vary if we had no data upon which to base our judgements. The likelihood informs about $\theta$ via the data itself. When we have a great deal of data the likelihood predominates, and our results will essentially be the maximum likelihood or traditional estimate. When we have fewer data, the prior has greater influence [22,23].

In general, combining studies through meta-analysis increases the power to find significant results and imposes a useful discipline on data synthesis by making the process of combining studies more organized and systematic than in traditional reviews. Additionally, a Bayesian approach allows us to make explicit what we often do implicitly, i.e. evaluate evidence given our expectations, and permits us to make predictions by calculating probabilities directly from the posterior distribution.

Among the weaknesses of a meta-analytical approach are that it requires some statistical expertise to properly conduct and interpret, that it is limited to close-ended quantitative formats, that information missing on unpublished studies may differ systematically from what is found in the literature, and in the event that the studies included in the synthesis may differ appreciably in type and conduct [24].

We searched published and unpublished post-1980 studies of quantitative population-level results of substance use and misuse following terrorist incidents. We excluded secondary analyses such as meta-analyses, qualitative results such as focus groups, editorials, review articles, commentaries and case reports. We limited our search to studies defined closely by time and place and excluded studies of torture, political repression, the effects of expatriation on political refugees, incidents of non-politically motivated violence such as criminal 
shootings and studies of potential threats, such as bioterrorist attacks, rather than actual incidents.

We defined substance use and misuse to include alcohol, cigarette, narcotics and prescription drugs, and terrorism as 'The intentional use of violence-real or threatened-against one or more non-combatants and/or those services essential for or protective of their health, resulting in adverse health effects in those immediately affected and their community, ranging from a loss of well-being or security to injury, illness, or death' [25].

Studies were eligible for analysis if they presented results in terms of proportions or prevalence, ORs of dichotomous variables, means with standard deviations, $P$-values, $t$-tests, $F$-statistics and $\chi^{2}$ or with data that could be translated into one of those terms. Where possible, analyses were based on extraction of raw data from tables and charts.

We searched electronically the following: PubMed, Medline, Cumulative Index of Nursing and Allied Health Literature (CINAHL), Allied and Complementary Medicine (AMED), PsychINFO, Health and Psychosocial Instruments, ProQuest Digital Dissertation Database, Papers First (a compendium of conference proceedings from the British Library), Cochrane Reviews, ACP Journal Club, Database of Abstracts of Reviews of Effectiveness (DARE), the Cochrane Controlled Trials Register (CCTR), Sociologic Abstracts and Web of Science by sequentially entering the terms: 'terrori* OR disaster', 'behavior*', 'subst* OR alcohol OR drug'.

Articles were entered into Endnote 9.0 [26]. We then searched for and excluded titles and text with references to natural and man-made disasters such as hurricanes, floods, storms, fires and chemical or toxicological spills. Primarily bioterrorism - threat-related articles were identified and excluded by searching for and visually inspecting references to 'smallpox, anthrax, plague, and radiologic'. References to night terrors and sleep disturbances were excluded by inspecting titles visually. To identify quantitative epidemiological studies, titles and abstract text were searched electronically for the terms: 'study, investigation, incidence, prevalence, proportion, effect, random*, population, research, cross-sectional, ecologic, and epidem*'. The references of remaining articles were inspected visually to identify additional articles.

Full-text versions of articles were reviewed by the primary author. Articles presenting additional or repeated analyses of previously published data were excluded to maintain the independence of studies entered into the analysis. Remaining studies were coded for the following variables: terrorist event (e.g. Oklahoma City Bombing, attacks of 11 September 2001, etc.), whether substance use was a primary or secondary end-point in the study, sample size, number and type of substance use-related outcomes, prevalence numbers, types and measures of association, sample type (treatment group, survivors, responders/employment, general population), age group (adult, pediatric, geriatric) and the number of months from the occurrence of the terrorist incident to the conduct of the study.

We entered data into Microsoft Excel and read into SAS version 9.2 [27] for descriptive analyses. We then entered data into Comprehensive Meta Analysis version 2 [28] to calculate effect sizes and variances for each study finding. The heterogeneity of the mean effect size for an outcome across studies was tested with a $Q$ statistic. If $Q$ is larger than the critical value of $\chi^{2}$ statistic with $k-1$ degrees of freedom, where $k$ is the number of effect sizes, we rejected a null hypothesis of homogeneity across effect sizes. We then entered the effect sizes for each finding into WinBUGS [29] and calculated overall effects with a Bayesian random effects model [30].

For studies reporting the results of population surveys of substance use or misuse, we based our Bayesian analyses on a binomial model. We calculated the natural log of the proportion of individuals who reported an increase in substance use or misuse and set this equal to a mean effect size, $\mu$, which was allowed to vary randomly as a normal distribution across studies. This normal distribution was given a mean of $\mathrm{d}$ and variance $\tau^{2}$. We placed a 'vague' or 'non-informative' prior expectation on this normal distribution of a zero mean and wide variance [Uniform $(0,10)]$.

Where sufficient numbers of studies were available, we created meta-regression models. With these models, we looked at how effect sizes varied by such study-level variables as time from which the incident occurred to the study was conducted, type of population under study and average age of the populations. We made inferences on such study-level variables by examining their beta coefficients in the regression model. In our Bayesian approach, we placed prior expectations on these beta coefficients, similar to the 'vague' or 'non-informative' Uniform $(0,10)$ prior distribution we placed on the overall effect size. We compared $\mathrm{m}$ on changes in study-to-study variance $\left(\tau^{2}\right)$ and on changes in deviance information criterion (DIC), a tool in WinBUGS analogous to the Akaike information criterion (AIC).

We tested our assumption of a Uniform $(0,10)$ prior distribution by conducting sensitivity analyses substituting normal and gamma prior distributions for the $\tau^{2}$ term and substituting more informative prior distributions for the d term, monitoring outcomes for changes from our baseline models.

We entered our models into WinBUGS and ran two 20000 Markov Chain Monte Carlo iterations, each starting with different and dispersed initial values for the model. We based our results on the final 10000 
iterations, and assessed whether the chain of values had converged to a stable posterior distribution by monitoring and assessing a graph of the chain as well as by calculating the Brooks Gellman and Rubin statistic, a tool within the WinBUGS program for this purpose.

The results are median values of the posterior distributions and their 95\% credible intervals (Cr I). Where appropriate, we exponentiated the logits which were used in the meta-analyses to present results in their original scale. Plots and graphs were created within the $\mathrm{R}$ statistical computing package [31]. The study protocol was approved by the Columbia University Institutional Review Board and complies with the Public Health Code of Ethics.

\section{RESULTS}

Thirty-nine studies were identified through electronic searches and review of abstracts. An additional six articles were identified from the references of these articles for a total of 44 studies. Of these, 10 studies were excluded because they were based on the same sample as a previous study, two articles were excluded because they did not present substance use or misuse results and one study was excluded because there were no numerical results. Thirty-one articles were eligible for entry into the analysis [3,6,8,14,16,17,20,32-55].

Of the 31 studies, 24 (77\%) were conducted after the terrorist attacks of 11 September 2001 in New York City and Washington DC. Four studies (13\%) were conducted following the Oklahoma City Bombing of 1995 and three studies $(10 \%)$ were conducted in the setting of the Intifada uprisings in Israel starting in 2001. The majority of studies $(58 \%)$ were designed explicitly to look at substance use and misuse. Thirteen studies (42\%) included substance use end-points as part of a larger study examining primarily psychiatric or mental health outcomes. Twenty-one studies (68\%) examined alcohol use and misuse as an end-point. Three studies (10\%) examined cigarette smoking as an exclusive primary end-point. Six studies (19\%) looked at multiple or mixed substance outcomes. Only one study looked explicitly and exclusively at narcotic use.

The largest number (45\%) of studies were based on general population samples, followed by out-patient clinical groups (23\%) and employment samples (16\%). Only three studies $(10 \%)$ examined data from survivors. Seventeen studies (55\%) were conducted within 6 months of a terrorist event. Five studies (16\%) were conducted longer than 1 year after a terrorist incident. Because of the way in which data were presented, not all studies contributed data to all analyses. A list of the studies included in the analysis and the areas of analysis to which they contributed are presented in Table 1 (see also supporting information detail at the end of this paper).
Table 1 Twenty-seven studies entered into meta-analysis of post-terrorism substance use and misuse and areas of analysis to which they contributed.

\begin{tabular}{|c|c|}
\hline Study (first author) & Contribution to analysis \\
\hline North (1999) [3] & $\begin{array}{l}\text { Association of alcohol use with } \\
\text { terrorism }\end{array}$ \\
\hline Pfefferbaum (2001) [32] & Increased alcohol use \\
\hline MMWR (2002) [71] & $\begin{array}{l}\text { Increased alcohol use/increased } \\
\text { smoking }\end{array}$ \\
\hline Factor (2002) [6] & $\begin{array}{l}\text { Association of alcohol use with } \\
\text { terrorism }\end{array}$ \\
\hline North (2002) [14] & Increased alcohol use \\
\hline Tucker (2002) [17] & Increased alcohol use \\
\hline Vlahov (2002) [8] & $\begin{array}{l}\text { Increased alcohol use/increased } \\
\text { smoking }\end{array}$ \\
\hline Gibson (2003) [35] & $\begin{array}{l}\text { Increased alcohol use/increased } \\
\text { smoking }\end{array}$ \\
\hline Grieger (2003) [36] & Increased alcohol use \\
\hline Rosenheck (2003) [20] & $\begin{array}{l}\text { Association of alcohol use with } \\
\text { terrorism }\end{array}$ \\
\hline Rosenheck (2003b) [37] & $\begin{array}{l}\text { Association of alcohol use with } \\
\text { terrorism }\end{array}$ \\
\hline Zywiak (2003) [38] & $\begin{array}{l}\text { Increased alcohol use/association } \\
\text { of alcohol use with terrorism }\end{array}$ \\
\hline Gould (2004) [39] & $\begin{array}{l}\text { Association of alcohol use with } \\
\text { terrorism }\end{array}$ \\
\hline Jordan (2004) [40] & Increased alcohol use \\
\hline Stein (2004) [43] & Mixed drug use \\
\hline Vlahov (2004) [7] & $\begin{array}{l}\text { Increased alcohol use/increased } \\
\text { smoking }\end{array}$ \\
\hline Bleich (2005) [45] & Mixed drug use \\
\hline Chiasson (2005) [46] & $\begin{array}{l}\text { Increased alcohol use/association } \\
\text { of alcohol Use with } \\
\text { terrorism/mixed drug use }\end{array}$ \\
\hline $\begin{array}{l}\text { Forman-Hoffman (2005) } \\
\quad[47]\end{array}$ & $\begin{array}{l}\text { Association of alcohol use with } \\
\text { terrorism }\end{array}$ \\
\hline Knudson (2005) [72] & $\begin{array}{l}\text { Association of alcohol use with } \\
\text { terrorism }\end{array}$ \\
\hline Simons (2005) [16] & Increased alcohol use \\
\hline Adams (2006) [50] & Increased alcohol use \\
\hline Dewart (2006) [51] & Mixed drug use \\
\hline Ford (2006) [52] & $\begin{array}{l}\text { Increased alcohol use/increased } \\
\text { smoking }\end{array}$ \\
\hline $\operatorname{Schiff}(2006)$ [53] & Increased alcohol use \\
\hline Wu (2006) [54] & $\begin{array}{l}\text { Increased alcohol use/increased } \\
\text { smoking }\end{array}$ \\
\hline Hasin (2007) [55] & Increased alcohol use \\
\hline
\end{tabular}

MMWR: Morbidity and Mortality Weekly Reports.

\section{Alcohol consumption}

Seventeen studies presented results on the prevalence of individuals reporting increased use of alcohol following terrorist attacks. No study reported a decrease in alcohol consumption. The unadjusted point estimate for the underlying prevalence of increased alcohol consumption following terrorist incidents was $9.3 \%$, with a $95 \% \mathrm{Cr}$ I of 5.4-15.4\% (synthesized unadjusted estimate, Fig. 1). 


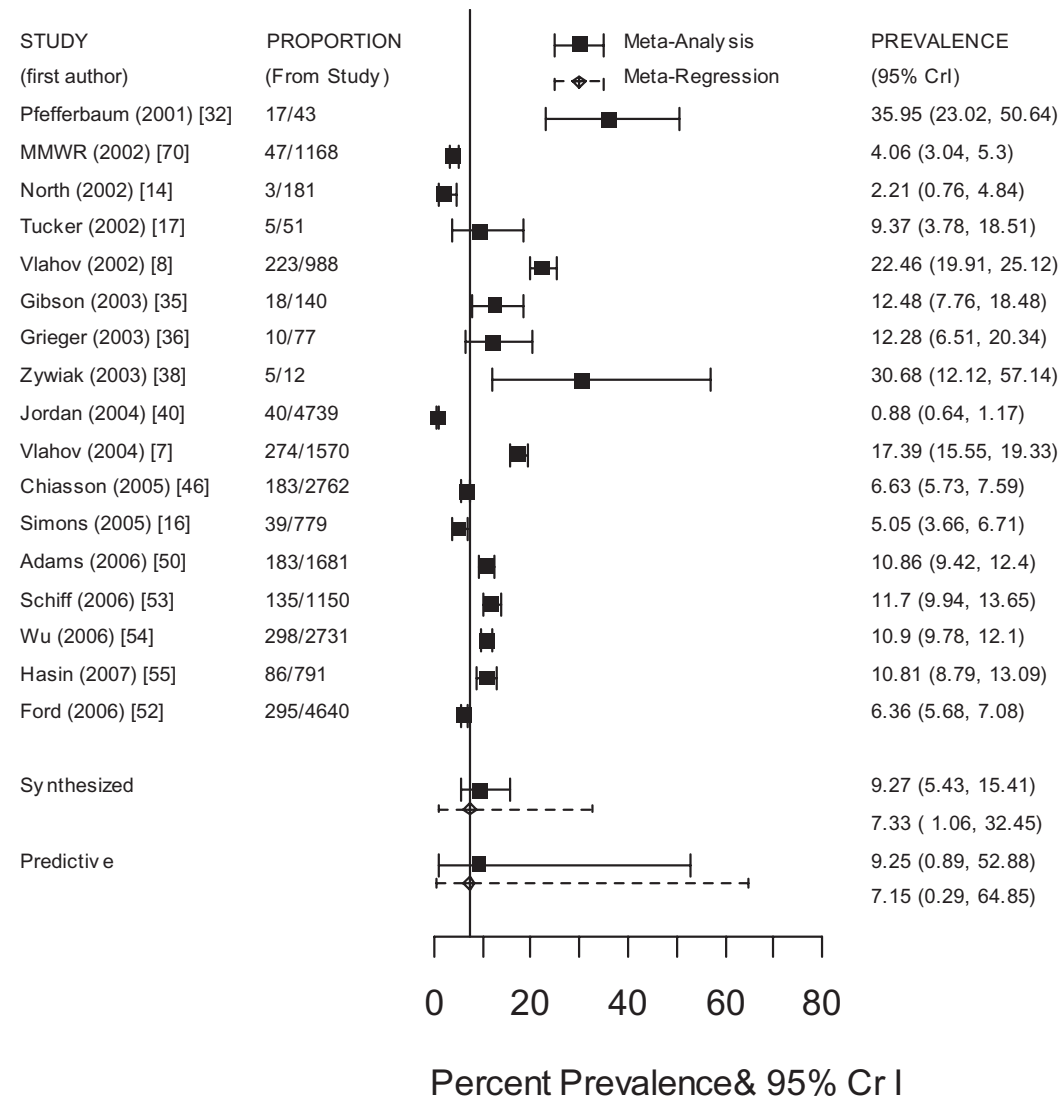

Figure I Forest plot of (I) percentage prevalence and $95 \%$ credible intervals from studies measuring proportion of population reporting increased alcohol consumption following terrorist incidents, and (2) comparison of synthesized and predictive estimates from metaanalysis and meta-regression. Solid line represents unadjusted synthesis of 17 studies. Dashed line represents meta-regression model controlling for study-level variables [meta-regression controlling for study-level estimates of time elapsed in months since incident, type of sample (treatment group, survivors, employment and first responders, general population), and incident (Oklahoma City bombing, terrorist attacks of II September 200 I, Palestinian Intifada in Israel)]. MMWR: Morbidity and Mortality Weekly Reports
Based on this estimate, a credible interval for a probability distribution predicting the proportion of a population with increased alcohol use after a terrorist attack would range from $0.8 \%$ to $52.9 \%$ around a mean of $9.3 \%$ (predictive unadjusted estimate, Fig. 1).

We entered study-level covariates for number of months from the date of the incidence until the study was conducted, population type (survivor, responder, treatment/rehabilitation, general population) and event (Oklahoma City Bombing, World Trade Center and Intifada) into a meta-regression model. Compared to the unadjusted model, none of the models with single covariates explained a greater proportion of the study-tostudy variance $\left(\tau^{2}\right)$, which remained 1.25 on the log odds scale, nor was there a meaningful change in the DIC across models. Each, however, resulted in meaningful changes in the point estimate for proportion of the population reporting increased alcohol use, indicating confounding. Controlling for number of months since the incident raised the estimate to $11.4 \%$ (95\% Cr I $4.7-$ $30 \%)$. Controlling for population type lowered the point estimate to $6.8 \%$ (95\% Cr I 2.6-19.4\%). Controlling for the event resulted in a similarly lowered estimate of $6.7 \%$ (95\% Cr I 2.0-18.9\%).

We included the three covariates in a single model. The point estimate for the meta-regression synthesis was $7.3 \%$ (95\% Cr I 1.1\%, 32.5\%) (synthesized metaregression estimate, Fig. 1). The beta coefficient for the effect of time in months from the occurrence of the event until the study was conducted was -0.04 (95\% Cr I-0.1, 0.03), suggesting a small and statistically non-important decline in prevalence over time. The beta coefficient for the effect of the event was 0.13 (95\% Cr I -0.5, 0.8). The effect of the type of population studied (arrayed as exposure increasing ordinally from general population to responders and employees to survivors) was similarly positive, with a point estimate for the beta coefficient of 0.25 (95\% Cr I -0.9, 1.2).

Figure 2 presents a probability plot based on this predictive distribution for increased alcohol use in a population following a terrorist incident. There is, for example, a $60 \%$ probability that at least $6 \%$ of an exposed population will report increased alcohol use. There is a $20 \%$ probability that at least $14 \%$ of an exposed population will report increased alcohol use. The wide credible bounds indicate that there is a great uncertainty underlying these estimates. As an example of this uncertainty, based on this predictive distribution, a future study of 1000 people would return a point estimate of $7.1 \%$ with a $95 \%$ credible interval of $0.2-66 \%$.

Nine studies contained information sufficient to calculate $\log \mathrm{ORs}$ for the association of the post-terrorist period 
Figure 2 Probability distribution for the proportion of a population reporting increased alcohol use following a terrorist incident (center line) with upper and lower credible intervals, based on synthesis of 17 studies

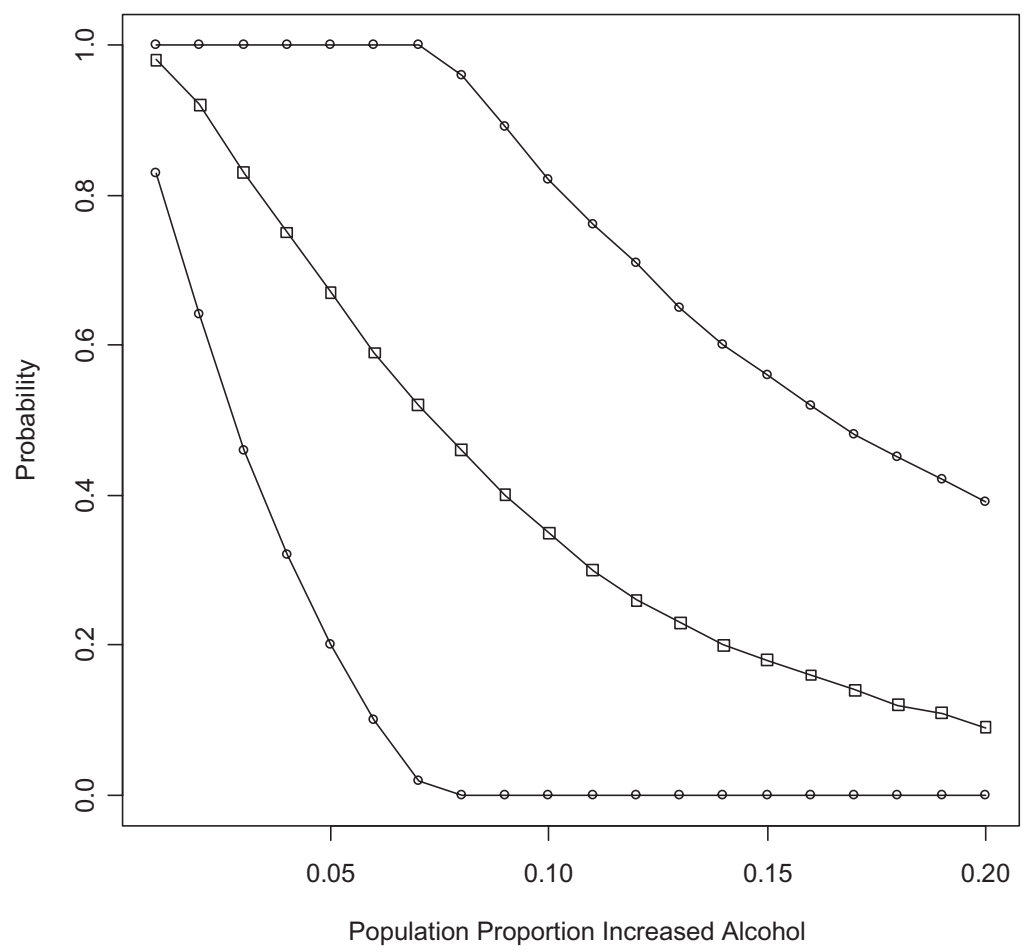

with increased alcohol consumption. The point estimate for the synthesis of this data was OR $=1.1$ with a $95 \%$ credible interval of $0.8-1.6$. The plot for the data (Fig. 3) demonstrates considerable variability of estimates, which is reflected in the predictive distribution. Based on the posterior distribution, the overall probability of an OR greater than 1 was $66 \%$, with a standard deviation for this estimate of $48 \%$.

\section{Smoking and mixed drug use}

Six studies presented data sufficient to investigate the prevalence of individuals reporting increased cigarette smoking following terrorist attacks. The unadjusted point estimate for the underlying prevalence of increased cigarette smoking following terrorist incidents was $6.8 \%$, with a $95 \%$ credible interval of $2.6-16.5 \%$ (Fig. 4). The probability that more than $15 \%$ of a post-terrorism population will report increased cigarette smoking was 3.2\%. There were no reports of decreased smoking.

Four studies presented results on the prevalence of individuals reporting increased use of narcotics, prescription medications and/or 'other drugs' following terrorist attacks. The unadjusted point estimate for the underlying prevalence of such increased 'mixed' drug use following terrorist incidents was $16.3 \%$ with a $95 \%$ credible interval of $1.3-72.5 \%$. The probability of more than $15 \%$ of an exposed population reporting such mixed drug use in a post-terrorism environment was 55\%.

\section{DISCUSSION}

This analysis suggests that the proportion of a population reporting alcohol misuse after exposure to terrorist events is probably substantially higher than the US National Institute on Alcohol Abuse and Alcoholism estimate that, under normal circumstances, the 12-month prevalence of alcohol abuse is $4.6 \%$ and of alcohol dependence is $3.8 \%$ [56].

There is ample reason to suggest that substance use in the population after mass trauma may indeed be different than it was before the mass traumatic incident. First, people who experience major trauma may use substances to relax and cope with stress and negative affect. This has been documented in the context of laboratory studies of smokers [57]. Secondly, people with anxiety disorders that are clearly associated with traumatic event experience may suffer exacerbated withdrawal symptoms, particularly irritability or nervousness [58]. Thirdly, people with anxiety disorders may well use drugs in an attempt to self-medicate symptoms [59]. Fourthly, once psychopathology has developed, substance use could exacerbate symptoms, interfering with the resolution of the traumatic experience and prolonging symptoms following the disaster.

That there have been reports of measureable physiological changes in response to exposure to terrorism in the absence of measurable changes in psychometric instruments [60] points out the importance of 


\begin{tabular}{ll}
$\begin{array}{l}\text { STUDY } \\
\text { (first author) }\end{array}$ & ESTIMATE \\
North (1999) [3] & $0.80(0.62,1.02)$ \\
\hline Factor (2002) [6] & $0.97(0.59,1.55)$ \\
\hline Rosenheck (2003) [20] & $0.86(0.76,0.98)$ \\
\hline Rosenheck (2003) [37] & $1.04(1.00,1.09)$ \\
\hline Zywiak (2003) [38] & $1.57(0.81,4.38)$ \\
\hline Gould (2004) [39] & $1.05(0.76,1.54)$ \\
\hline Knudson (2003) [72] & $0.73(0.52,1.02)$ \\
\hline Chiasson (2005) [46] & $1.78(1.40,2.27)$ \\
\hline & \\
\hline & \\
\hline & \\
\hline & \\
\hline
\end{tabular}

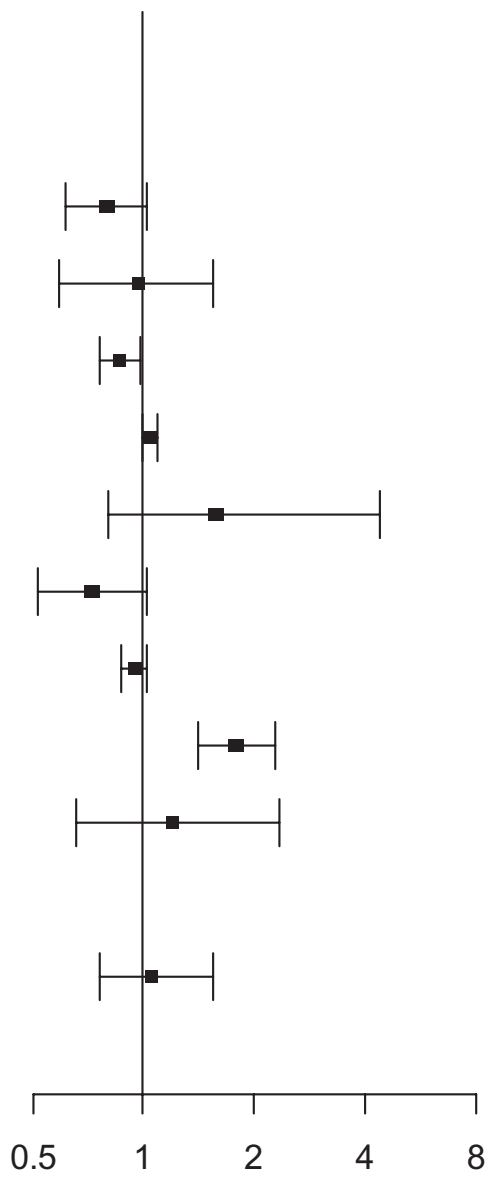

Odds Ratio \& 95\% Cr I
Figure 3 Plot comparing odds ratios and 95\% credible intervals (CRI) (on log scale) for the meta-analysis of nine studies measuring the association of the post-terrorism time period with increased alcohol consumption along with the synthesized point estimate understanding the underlying pathophysiology of behavioral responses such as substance use and misuse. Epigenetics will play an increasingly important role in this endeavor [61,62]. Understanding the population health effects of stressors such as fear of terrorism can help to inform such basic research.

It is clear from our results that there is great variability in the estimates of substance use prevalence after terrorism. Variability is due, at least in part, to the time elapsed from the event. Controlling for the time elapsed from the incident until the study was conducted changed the point estimate for prevalence of increased drinking. Similarly, the population sampled and the type of event can be expected to affect the prevalence, because of the differences in exposure intensity and duration. For example, younger Red Cross workers who experienced intrusive thoughts were more likely to report increased alcohol use in response to the terrorist attacks of 11 September 2001 [63].

Two studies published after this meta-analysis was completed may shed additional light on the findings. In the first, based on a telephone survey of a prospectively followed national cohort, little change was reported in smoking or drinking following the terrorist attacks of 11 September 2001. Interestingly, the emotional reactions of those who did report increased smoking differed from those who reported increased drinking [64]. In a second recent study, also based on a prospectively followed cohort, this time from the Midwest, fear of terrorism predicted subsequent 'distress and drinking outcomes' [65].

The body of literature relating combat experience to increased substance use and misuse may also be informative [66-68]. Current reports echo those of past conflicts, with combat exposure associated with 50-60\% increased risk of the onset of heavy drinking and binge drinking [69]. It is not yet clear if this behavior is being driven by fear, anger or depression, or perhaps even by a sense of invincibility after having survived intense periods of danger [70]. One can hypothesize similar reactions on the part of survivors, rescuers and local populations confronted with terrorism.

This study was subject to a number of potential limitations. Only a small number of data points went into the meta-regression, although the results are consistent with the observation, common in research about exposure to traumatic events, that severity of exposure is probably 


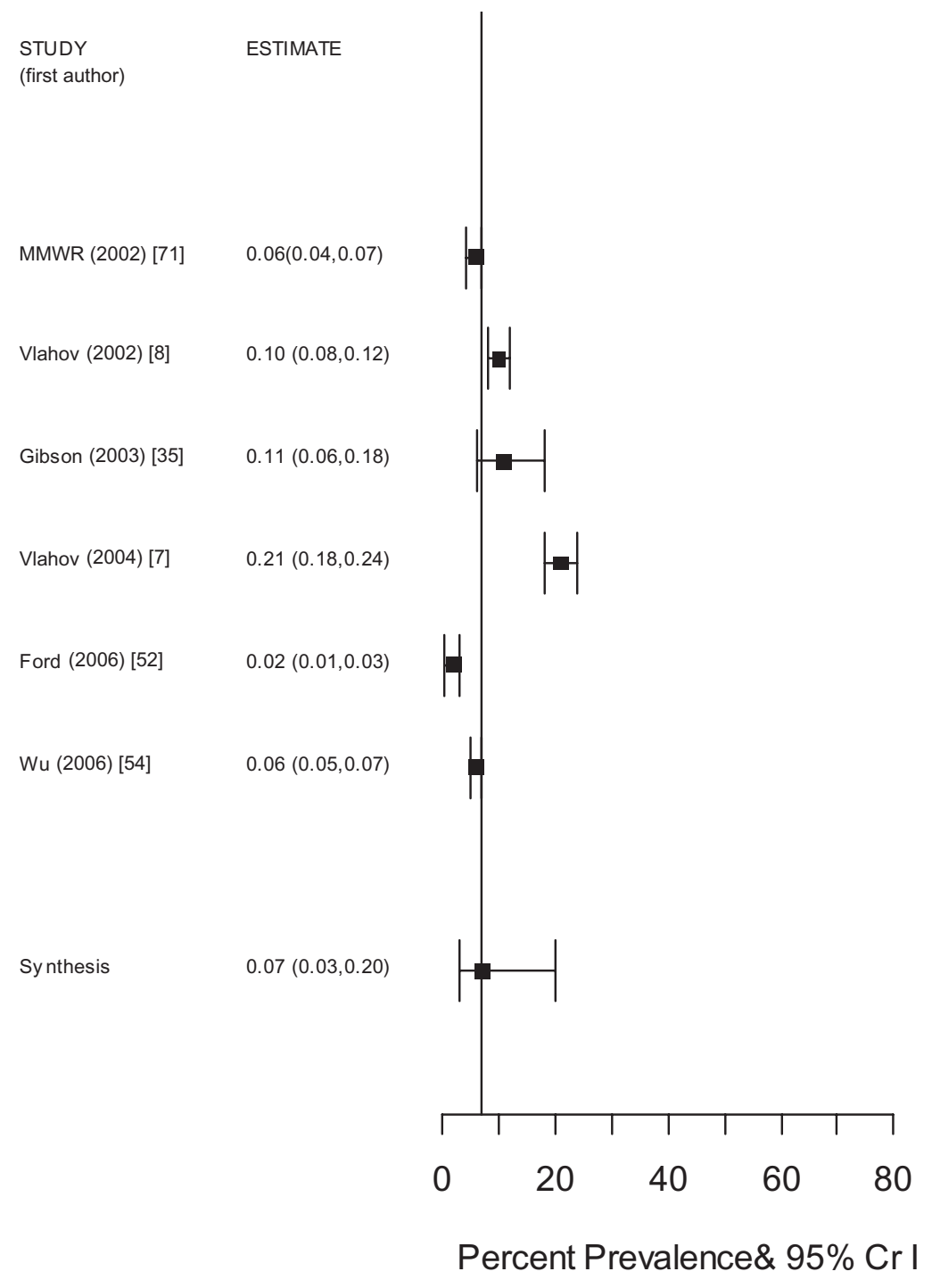

the single most important determinant of the adverse behavioral consequences of terrorist attacks. Similarly, while statistical assessments of covariates were limited by the small number of data points, the appreciable change in the estimate of increased alcohol use when adjusted for covariates clearly indicated confounding.

Our study was also subject to publication bias. The predominance of studies addressing the terrorist attacks of 11 September 2001 reflects the published research literature, but does not reflect world-wide exposure to terrorism [5].

In general, meta-analyses should be interpreted cautiously. Summary statistics, while useful in many respects, must not be allowed to obscure theory. Studies may be so heterogeneous as to challenge the basis of combining them, and there may be undetected systematic variation among studies. We tried to address this by addressing explicitly the random effects component of our model through meta-regression.

Our use of a Bayesian approach allowed us to outline and state explicitly our prior assumptions about how studies would probably vary. It had the added benefit of allowing us to calculate probabilities directly from the posterior distribution. In this manner we were able to state how likely it is that alcohol consumption will reach certain levels of prevalence.

These summary findings suggest that public health interventions after terrorist incidence should recognize the potential for substance use and misuse in communities following such events. By pooling the available evidence, our results may help to guide potential population-level interventions to facilitate and speed the process of recovery by helping to estimate the proportion and types of individuals at risk of substance use and misuse following mass trauma. Interventions may also benefit from recognition that interventions may be most apt soon after the event, and that some individuals such as survivors, rescuers and those with a history or 
substance use and misuse may be at increased risk and will require additional surveillance, assessments and perhaps individual interventions.

\section{Declarations of interest}

None.

\section{Acknowledgements}

This research was supported by grants R03DA023431 and R01AA09963 from the National Institutes of Health. The Bayesian analytic approaches used in the study were based on material presented by Keith Abrams, Tony Ades, Nocola Cooper, Alex Sutton and Nicky Welton as part of 'Evidence Building for Decision Modeling' held in Boston, MA, USA, April 2008.

\section{References}

1. Galea S., Ahern J., Resnick H., Kilpatrick D., Bucuvalas M., Gold J. et al. Psychological sequelae of the September 11 terrorist attacks in New York city. N Engl J Med 2002; 346: 982-7.

2. Munoz M., Crespo M., Perez-Santos E., Vazquez J. J. Early psychological consequences of the March 11, 2004, terrorist attacks in Madrid, Spain. Psychol Rep 2005; 97: 907-20.

3. North C. S., Nixon S. J., Shariat S., Mallonee S., McMillen J. C., Spitznagel E. L. et al. Psychiatric disorders among survivors of the Oklahoma City bombing. JAMA 1999; 282: 755-62.

4. Rubin G. J., Brewin C. R., Greenberg N., Simpson J., Wessely S. Psychological and behavioural reactions to the bombings in London on 7 July 2005: cross sectional survey of a representative sample of Londoners. BMJ 2005; 331: 606.

5. DiMaggio C., Galea S. The behavioral consequences of terrorism: a meta-analysis. Acad Emerg Med 2006; 13: 559-66.

6. Factor S. H., Wu Y., Monserrate J., Edwards V., Cuevas Y., Del Vecchio S. et al. Drug use frequency among street-recruited heroin and cocaine users in Harlem and the Bronx before and after September 11, 2001. J Urban Health 2002; 79: 404-8.

7. Vlahov D., Galea S., Ahern J., Resnick H., Kilpatrick D. Sustained increased consumption of cigarettes, alcohol, and marijuana among Manhattan residents after September 11, 2001. Am J Public Health 2004; 94: 253-4.

8. Vlahov D., Galea S., Resnick H., Ahern J., Boscarino J. A., Bucuvalas M. et al. Increased use of cigarettes, alcohol, and marijuana among Manhattan, New York, residents after the September 11th terrorist attacks. Am J Epidemiol 2002; 155: 988-96.

9. Silver R. C., Holman E. A., McIntosh D. N., Poulin M., Gil-Rivas V. Nationwide longitudinal study of psychological responses to September 11. JAMA 2002; 288: 1235-44.

10. Fagan J., Galea S., Ahern J., Bonner S., Vlahov D. Relationship of self-reported asthma severity and urgent health care utilization to psychological sequelae of the September 11, 2001 terrorist attacks on the World Trade Center among New York City area residents. Psychosom Med 2003; 65: 993-6.

11. Halkitis P. N., Kutnick A. H., Rosof E., Slater S., Parsons J. T.
Adherence to HIV medications in a cohort of men who have sex with men: impact of September 11th. J Urban Health 2003; 80: 161-6.

12. Nandi A., Galea S., Ahern J., Vlahov D. Probable cigarette dependence, PTSD, and depression after an urban disaster: results from a population survey of New York City residents 4 months after September 11, 2001. Psychiatry 2005; 68: 299-310.

13. Moore R. S., Cunradi C. B., Ames G. M. Did substance use change after September llth? An analysis of a military cohort. Mil Med 2004; 169: 829-32.

14. North C. S., Tivis L., McMillen J. C., Pfefferbaum B., Spitznagel E. L., Cox J. et al. Psychiatric disorders in rescue workers after the Oklahoma City bombing. Am J Psychiatry 2002; 159: 857-9.

15. North C. S., Pfefferbaum B., Narayanan P., Thielman S., McCoy G., Dumont C. et al. Comparison of post-disaster psychiatric disorders after terrorist bombings in Nairobi and Oklahoma City. Br J Psychiatry 2005; 186: 487-93.

16. Simons J. S., Gaher R. M., Jacobs G. A., Meyer D., JohnsonJimenez E. Associations between alcohol use and PTSD symptoms among American Red Cross disaster relief workers responding to the 9/11/2001 attacks. Am J Drug Alcohol Abuse 2005; 31: 285-304.

17. Tucker P., Pfefferbaum B., Doughty D. E., Jones D. E. Body handlers after terrorism in Oklahoma City: predictors of posttraumatic stress and other symptoms. Am J Orthopsychiatry 2002; 72: 469-75.

18. Norris F. H., Friedman M. J., Watson P. J., Byrne C. M., Diaz E., Kaniasty K. 60,000 disaster victims speak: part I. An empirical review of the empirical literature, 1981-2001. Psychiatry 2002; 65: 207-39.

19. Curran P. S., Gregg W. Psychiatric aspects of terrorist violence in Northern Ireland (1969 to 1989). Med Leg J 1990; 58: 83-96.

20. Rosenheck R., Fontana A. Use of mental health services by veterans with PTSD after the terrorist attacks of September 11. Am J Psychiatry 2003; 160: 1684-90.

21. Satel S. L. The mental health crisis that wasn't. Psychiatr Serv 2003; 54: 1571.

22. Greenland S. Bayesian perspectives for epidemiological research: I. Foundations and basic methods. Int J Epidemiol 2006; 35: 765-75.

23. Lawson A., Browne W., Vidal Rodeiro C. Disease Mapping with WinBUGS and Elwin. West Sussex: John Wiley and Sons Ltd.; 2003.

24. Lipsey M. W., Wilson D. B. Practical Meta-Analysis. Thousand Oaks, CA: Sage Publications; 2001.

25. Arnold J. L., Ortenwall P., Birnbaum M. L., Sundnes K. O., Aggrawal A., Anantharaman V. et al. A proposed universal medical and public health definition of terrorism. Prehospital Disaster Med 2003; 18: 47-52.

26. Thomson Reuters. Endnote version 10.1. Philadelphia, PA: Thomson Research Soft; 2005.

27. SAS Institute. SAS version 9.1.3. Cary, NC: SAS Institute; 2006.

28. Biostat Comprehensive. Meta Analysis Version 2.2. Englewood, NJ: Biostat; 2007.

29. Imperial College and Medical Research Council. WinBUGS version 1.4.1. London, UK: Imperial College and Medical Research Council; 2004.

30. Spiegelhalter D. J., Abrams K., Myles J. P. Bayesian Approaches to Clinical Trials and Health-Care Evaluation. West Sussex: John Wiley \& Sons, Ltd.; 2006. 
31. R Development Core Team. R: A Language and Environment for Statistical Computing. Vienna, Austria: R Development Core Team; 2006. http://cran.r-project.org/doc/manuals/ refman.pdf (accessed 26 March 2009).

32. Pfefferbaum B., Doughty D. E. Increased alcohol use in a treatment sample of Oklahoma City bombing victims. Psychiatry 2001; 64: 296-303.

33. Centers for Disease Control and Prevention. Psychological and emotional effects of the September 11 attacks on the World Trade Center-Connecticut, New Jersey, and New York, 2001. JAMA 2002; 288: 1467-8.

34. Creson D. L., Schmitz J. M., Sayre S. L., Rhoades H. M. Stress and behavior change in a substance-abusing population following September 11, 2001. Addictive Disorders \& Their Treatment 2003; 2: 59-61.

35. Gibson M., Iwaniec D. An empirical study into the psychosocial reactions of staff working as helpers to those affected in the aftermath of two traumatic incidents. Br J Soc Work 2003; 33: 851-69.

36. Grieger T. A., Fullerton C. S., Ursano R. J. Posttraumatic stress disorder, alcohol use, and perceived safety after the terrorist attack on the pentagon [see comment]. Psychiatr Serv 2003; 54: 1380-2.

37. Rosenheck R. A., Fontana A. Post-September 11 admission symptoms and treatment response among veterans with posttraumatic stress disorder. Psychiatr Serv 2003; 54: 1610-17.

38. Zywiak W. H., Stout R. L., Trefry W. B., LaGrutta J. E., Lawson C. C., Khan N. et al. Alcohol relapses associated with September 11, 2001: a case report. Subst Abus 2003; 24: $123-8$.

39. Gould M. S., Munfakh J. L. H., Kleinman M., Lubell K., Provenzano D. Impact of the September 11th terrorist attacks on teenagers' mental health, Appl Dev Sci 2004; 8: 158-69.

40. Jordan N. N., Hoge C. W., Tobler S. K., Wells J., Dydek G. J., Egerton W. E. Mental health impact of 9/11 Pentagon attack: validation of a rapid assessment tool. Am J Prev Med 2004; 26: 284-93.

41. Perrine M. W., Schroder K. E., Forester R., McGonagleMoulton P., Huessy F. The impact of the September 11, 2001 , terrorist attacks on alcohol consumption and distress: reactions to a national trauma 300 miles from Ground Zero. J Stud Alcohol 2004; 65: 5-15.

42. Richman J. A., Wislar J. S., Flaherty J. A., Fendrich M., Rospenda K. M. Effects on alcohol use and anxiety of the September 11, 2001, attacks and chronic work stressors: a longitudinal cohort study. Am J Public Health 2004; 94: 2010-15.

43. Stein B. D., Elliott M. N., Jaycox L. H., Collins R. L., Berry S. H., Klein D. J. et al. A national longitudinal study of the psychological consequences of the September 11, 2001 terrorist attacks: reactions, impairment, and help-seeking. Psychiatry 2004; 67: 105-17.

44. Vlahov D., Galea S., Ahern J., Resnick H., Boscarino J. A., Gold J. et al. Consumption of cigarettes, alcohol, and marijuana among New York City residents six months after the September 11 terrorist attacks. Am J Drug Alcohol Abuse 2004; 30: 385-407.

45. Bleich A., Gelkopf M., Melamed Y., Solomon Z. Emotional impact of exposure to terrorism among young-old and oldold Israeli citizens. Am J Geriatr Psychiatry 2005; 13: 70512.

46. Chiasson M. A., Hirshfield S., Humberstone M., Difilippi J.,
Koblin B. A., Remien R. H. Increased high risk sexual behavior after September 11 in men who have sex with men: an Internet survey. Arch Sex Behav 2005; 34: 527-35.

47. Forman-Hoffman V., Riley W., Pici M. Acute impact of the September 11 tragedy on smoking and early relapse rates among smokers attempting to quit. Psychol Addict Behav 2005; 19: 277-83.

48. Knudsen H. K., Roman P. M., Johnson J. A., Ducharme L. J. A changed America? The effects of September 11th on depressive symptoms and alcohol consumption. J Health Soc Behav 2005; 46: 260-73.

49. Weissman M. M., Neria Y., Das A., Feder A., Blanco C., Lantigua R. et al. Gender differences in posttraumatic stress disorder among primary care patients after the World Trade Center attack of September 11, 2001. Gend Med 2005; 2: 76-87.

50. Adams R. E., Boscarino J. A., Galea S. Alcohol use, mental health status and psychological well-being 2 years after the World Trade Center attacks in New York City. Am J Drug Alcohol Abuse 2006; 32: 203-24.

51. Dewart T., Frank B., Schmeidler J. The impact of $9 / 11$ on patients in New York City's substance abuse treatment programs. Am J Drug Alcohol Abuse 2006; 32: 665-72.

52. Ford J. D., Adams M. L., Dailey W. F. Factors associated with receiving help and risk factors for disaster-related distress among Connecticut adults 5-15 months after the September 11th terrorist incidents. Soc Psychiatry Psychiatr Epidemiol 2006; 41: 261-70.

53. Schiff M. Living in the shadow of terrorism: psychological distress and alcohol use among religious and non-religious adolescents in Jerusalem. Soc Sci Med 2006; 62: 2301-12.

54. Wu P., Duarte C. S., Mandell D. J., Fan B., Liu X., Fuller C. J. et al. Exposure to the World Trade Center attack and the use of cigarettes and alcohol among New York City public highschool students. Am J Public Health 2006; 96: 804-7.

55. Hasin D. S., Keyes K. M., Hatzenbuehler M. L., Aharonovich E. A., Alderson D. Alcohol consumption and posttraumatic stress after exposure to terrorism: effects of proximity, loss, and psychiatric history. Am J Public Health 2007; 97: 226875.

56. Grant B. F., Dawson D. A., Stinson F. S., Chou S. P., Dufour M. C., Pickering R. P. The 12-month prevalence and trends in DSM-IV alcohol abuse and dependence: United States, 1991-1992 and 2001-2002. Drug Alcohol Depend 2004; 74: 223-34.

57. Gilbert D. G., Robinson J. H., Chamberlin C. L., Spielberger C. D. Effects of smoking/nicotine on anxiety, heart rate, and lateralization of EEG during a stressful movie. Psychophysiology 1989; 26: 311-20.

58. Beckham J. C., Lytle B. L., Vrana S. R., Hertzberg M. A., Feldman M. E., Shipley R. H. Smoking withdrawal symptoms in response to a trauma-related stressor among Vietnam combat veterans with posttraumatic stress disorder. Addict Behav 1996; 21: 93-101.

59. Stewart S. H., Pihl R. O., Conrod P. J., Dongier M. Functional associations among trauma, PTSD, and substance-related disorders. Addict Behav 1998; 23: 797-812.

60. Tucker P. M., Pfefferbaum B., North C. S., Kent A., Burgin C. E., Parker D. E. et al. Physiologic reactivity despite emotional resilience several years after direct exposure to terrorism. Am J Psychiatry 2007; 164: 230-5.

61. Bleich S., Lenz B., Ziegenbein M., Beutler S., Frieling H., Kornhuber J. et al. Epigenetic DNA hypermethylation of the HERP gene promoter induces down-regulation of its mRNA 
expression in patients with alcohol dependence. Alcohol Clin Exp Res 2006; 30: 587-91.

62. Bonsch D., Lenz B., Fiszer R., Frieling H., Kornhuber J., Bleich S. Lowered DNA methyltransferase (DNMT-3b) mRNA expression is associated with genomic DNA hypermethylation in patients with chronic alcoholism. J Neural Transm 2006; 113: 1299-304.

63. Gaher R. M., Simons J. S., Jacobs G. A., Meyer D., JohnsonJimenez E. Coping motives and trait negative affect: testing mediation and moderation models of alcohol problems among American Red Cross disaster workers who responded to the September 11,2001 terrorist attacks. Addict Behav 2006; 31: 1319-30.

64. Pfefferbaum B., North C. S., Pfefferbaum R. L., Christiansen E. H., Schorr J. K., Vincent R. D. et al. Change in smoking and drinking after September 11, 2001, in a national sample of ever smokers and ever drinkers. J Nerv Ment Dis 2008; 196: 113-21.

65. Richman J. A., Cloninger L., Rospenda K. M. Macrolevel stressors, terrorism, and mental health outcomes: broadening the stress paradigm. Am J Public Health 2008; 98: S11319.

66. Branchey L., Davis W., Lieber C. S. Alcoholism in Vietnam and Korea veterans: a long term follow-up. Alcohol Clin Exp Res 1984; 8: 572-5.

67. McFall M. E., Mackay P. W., Donovan D. M. Combat-related posttraumatic stress disorder and severity of substance abuse in Vietnam veterans. J Stud Alcohol 1992; 53: 357-63.

68. Parette H. P. Jr, Farrow B. J., Farrow J. M., Hazelwood M. The aging war veteran and alcohol abuse: an emerging relationship? Percept Mot Skills 1989; 68: 985-6.

69. Jacobson I. G., Ryan M. A., Hooper T. I., Smith T. C., Amoroso P. J., Boyko E. J. et al. Alcohol use and alcohol- related problems before and after military combat deployment. JAMA 2008; 300: 663-75.

70. Killgore W. D., Cotting D. I., Thomas J. L., Cox A. L., McGurk D., Vo A. H. et al. Post-combat invincibility: violent combat experiences are associated with increased risk-taking propensity following deployment. J Psychiatr Res 2008; 42: 1112-21.

71. Knudsen H. K., Roman P. M., Johnson J. A., Ducharme L. J. A changed America? The effects of September 11th on depressive symptoms and alcohol consumption. J Health Soc Behav 2005; 46: 260-73.

72. MMWR (Morbidity and Mortality Weekly Reports). From the Centers for Disease Control and Prevention. Psychological and emotional effects of the September 11 attacks on the World Trade Center-Connecticut, New Jersey, and New York. MMWR 2002; 51: 784-6.

\section{Supporting information}

Additional Supporting Information may be found in the online version of this article:

Appendix S1 Full bibliographic information and inclusion/exclusion determination for 44 studies that met initial inclusion criteria

Please note: Wiley-Blackwell is not responsible for the content or functionality of any supporting materials supplied by the authors. Any queries (other than missing material) should be directed to the corresponding author for the article. 